\title{
Notificação e identificação do abuso sexual de vulnerável por meio de alterações orofaciais e aspectos comportamentais no ambiente odontológico
}

\author{
Notification and identification of sexual abuse of a vulnerable person through orofacial changes \\ and behavioral aspects in the dental environment \\ Notificación e identificación de abuso sexual de una persona vulnerable a través de cambios \\ orofaciales y aspectos conductuales en el entorno dental
}

Recebido: 27/10/2021 | Revisado: 06/11/2021 | Aceito: 06/11/2021 | Publicado: 10/11/2021

\author{
Nayara Guimarães Loiola \\ ORCID: https://orcid.org/0000-0002-7454-3548 \\ Faculdade Patos de Minas, Brasil \\ E-mail: nayaraloiola123@gmail.com \\ Lia Dietrich \\ ORCID: https://orcid.org/0000-0001-7887-8591 \\ Universidade Federal dos Vales do Jequitinhonha e Mucuri, Brasil \\ E-mail: lia.dietrich@ufvjm.edu.br \\ Cláudia Maria de Oliveira Andrade \\ ORCID: https://orcid.org/0000-0003-4529-8106 \\ Faculdade Patos de Minas, Brasil \\ E-mail: claudia.andrade@faculdadepatosdeminas.edu.br
}

\begin{abstract}
Resumo
O presente trabalho tem como objetivo contribuir aos profissionais da área de Odontologia, informações sobre identificação e notificação de abuso sexual no ambiente odontológico, por meio da análise comportamental e de manifestações orofaciais. Este estudo consiste de revisão de literatura, qualitativa do tipo integrativa. Por meio de consultas nas bases de dados: Google Acadêmico, SciELO, BVS, e PubMed, foram buscados artigos entre os anos de 1990 a 2021, preferencialmente com as palavras chaves: Abuso Sexual Infantil, Notificação Compulsória de Abuso, e Infecção Sexualmente Transmissível. O abuso sexual infantil muitas vezes não é diagnosticado e nem notificado, sendo o cirurgião-dentista obrigado a notificar situações suspeitas ou confirmação de maus tratos, de acordo com o Estatuto da Criança e do Adolescente - ECA. Entretanto, existe pouco conhecimento sobre à violência infantil, dificuldade na identificação dos principais sinais/manifestações do abuso sexual e dúvidas sobre como proceder diante os casos, sendo necessário orientação profissional ao cirurgião-dentista, para ajudá-lo tanto no diagnóstico, quando no registro da violência infantil. A comunidade odontológica é essencial no diagnóstico/ prevenção dos maus tratos, no tratamento das lesões orofaciais derivadas do abuso e auxilio nas notificações da violência infantil, devendo ser conscientizada sobre o combate ao abuso e negligências infantis, levando em consideração, que pode responder legalmente a não realização das deliberações do ECA. Conclui-se que lesões provenientes dos maus tratos, inclusive do abuso sexual, comprometem a região orofacial, sendo indispensável que cirurgiões-dentistas estejam aptos para identificar e denunciar os casos de suspeita de abuso sexual de vulnerável.
\end{abstract}

Palavras-chave: Abuso sexual infantil; Notificação compulsória de abuso; Infecção sexualmente transmissível.

\begin{abstract}
The present work aims to contribute to professionals in the field of Dentistry, information on the identification and notification of sexual abuse in the dental environment, through behavioral analysis and orofacial manifestations. This study consists of a literature review, qualitative of the integrative type. Through queries in the databases: Academic Google, SciELO, BVS, and PubMed, articles were searched between the years 1990 to 2021, preferably with the keywords: Child Sexual Abuse, Compulsory Notification of Abuse, and Sexually Transmitted Infection. Child sexual abuse is often not diagnosed or notified, and the dentist is obliged to notify suspicious situations or confirmation of abuse, in accordance with the Statute of Children and Adolescents - ECA. However, there is little knowledge about child violence, difficulty in identifying the main signs/manifestations of sexual abuse and doubts about how to proceed in these cases, requiring professional guidance to the dental surgeon to help with both diagnosis and registration of child violence. The dental community is essential in the diagnosis/prevention of maltreatment, in the treatment of orofacial injuries resulting from abuse and assistance in reporting child violence, and must be made aware of the fight against child abuse and neglect, taking into account that it can legally respond to failure to carry out the deliberations of the ECA. It is concluded that injuries resulting from mistreatment, including sexual abuse, compromise the
\end{abstract}


orofacial region, and it is essential that dentists are able to identify and report cases of suspected sexual abuse of a vulnerable person.

Keywords: Child sexual abuse; Compulsory notification of abuse; Sexually transmitted infection.

\section{Resumen}

El presente trabajo tiene como objetivo aportar a los profesionales del campo de la Odontología, información sobre la identificación y notificación de abusos sexuales en el ámbito odontológico, a través del análisis conductual y las manifestaciones orofaciales. Este estudio consiste en una revisión de la literatura, cualitativa de tipo integrativo. Mediante consultas en las bases de datos: Google Academic, SciELO, BVS y PubMed, se buscaron artículos entre los años 1990 a 2021, preferentemente con las palabras clave: Abuso Sexual Infantil, Notificación Obligatoria de Abuso e Infección de Transmisión Sexual. El abuso sexual infantil a menudo no se diagnostica ni se notifica, y el dentista está obligado a notificar situaciones sospechosas o confirmación de abuso, de acuerdo con el Estatuto de la Niñez y la Adolescencia - ECA. Sin embargo, existe poco conocimiento sobre la violencia infantil, dificultad para identificar los principales signos / manifestaciones de abuso sexual y dudas sobre cómo proceder en estos casos, requiriendo orientación profesional al cirujano dentista para ayudar tanto en el diagnóstico como en el registro de la violencia infantil. La comunidad odontológica es fundamental en el diagnóstico / prevención del maltrato, en el tratamiento de las lesiones orofaciales resultantes del maltrato y la asistencia en la denuncia de la violencia infantil, y debe ser consciente de la lucha contra el maltrato y el abandono infantil, teniendo en cuenta que puede legalmente responder al incumplimiento de las deliberaciones del TCE. Se concluye que las lesiones derivadas del maltrato, incluido el abuso sexual, comprometen la región orofacial, y es fundamental que los odontólogos puedan identificar y denunciar los casos de sospecha de abuso sexual de una persona vulnerable.
\end{abstract}

Palabras clave: Abuso sexual infantil; Notificación obligatoria de abuso; Infección trasmitida sexualmente.

\title{
1. Introdução
}

A violência infantil se constitui um grande problema social. Maus-tratos contra crianças podem ser divididos conforme a natureza dos atos agressivos em: abuso físico, abuso sexual, abuso psicológico e negligência. A partir disso, o presente trabalho terá ênfase no abuso sexual de vulneráveis que se caracteriza por prática do ato sexual infantil entre adultos e indivíduos menores de 18 anos (Alves, Da Fonseca, Soares, \& Alexandria, 2016; Carneiro, 2020; Pires, \& Miyazaki, 2005; Silva et al., 2011).

Pornografia e prostituição, contato oral, anal e vaginal seguido ou não de penetração, assédio sexual e ato libidinoso constituem as formas clássicas de abuso sexual contra vulneráveis, deixando como sequelas gravidez, infecções venéreas, danos psicológicos e quadros de sequelas físicas e fisiológicas. Grande parte dos casos, o agressor é membro da família, assim como em casos de abusos de repetição (Pires, \& Miyazaki, 2005; Granville-Garcia, Silva \& Menezes, 2006; Silva et al., 2011).

No Brasil, em 13 de julho de 1.990 foi criado o Estatuto da Criança e do Adolescente - ECA, por meio do decreto da lei $\mathrm{n}^{\circ} 8.069$, pela qual garante os direitos e deveres da criança e do adolescente (Brasil, 1990).

Pode acontecer do abuso não deixar visível suas manifestações ou o agressor pode tentar ocultar os vestígios, sendo de extrema importância que o cirurgião-dentista observe o comportamento da vítima. Crianças abusadas sexualmente são afetadas psicologicamente, produzindo comportamentos indicadores de abuso sexual, como exemplo agressividade, falta de atenção, hiperatividade, isolamento social, indisposição, tentativa de suicídio e tentativas de automutilações (Silva, Gava \& Dell’Aglio, 2013; Conceição, Costa, Penso \& Wiliiams, 2020).

O abuso sexual infantil pode ser identificado por meio de manifestações clínicas orofaciais como laceração de freio labial e lingual, mordidas acompanhadas de equimose de sucção. Algumas infecções transmissíveis sexualmente, como o HPV, tem repercussão oral a partir de lesões verrucosas, logo, o cirurgião-dentista tem um papel importante na identificação do delito, justamente por ter um íntimo contato com as regiões afetadas (Crespo, Andrade, Alves, \& Magalhães, 2011; FisherOwens, Lukefahr \& Tate, 2017).

O cirurgião-dentista deve saber identificar e notificar o abuso sexual de vulnerável por lidar com regiões que apresentam manifestações do abuso sexual. O conhecimento sobre o tema pode auxiliar gestores da saúde nos projetos de ação contra o abuso sexual infantil (Santos \& Ippolito, 2009). 
Este estudo se apresenta relevante para o ramo da Odontologia, pelo fato de parte das manifestações provenientes do abuso sexual estarem localizadas em regiões de íntimo contato do profissional, como região orofacial, cabeça e pescoço (Alves et al., 2016; Salazar, Sá \& Veloso, 2021).

Pelo fato do cirurgião-dentista ter a possibilidade de criar vínculo com seus pacientes, principalmente em procedimentos com mais de uma sessão, a análise comportamental deve ser avaliada e reavaliada, além de somada as condições clínicas. Essa análise comportamental é de extrema importância nos casos de abuso sexual sem manifestações orofaciais, corporais ou tentativa de ocultação das manifestações clínicas (Conceição et al., 2020; Silva et al., 2013).

A notificação e tratamento das vítimas de abuso sexual contribuem para diminuição de problemas sociais, pelo fato dos danos psicológicos repercutirem de forma negativa nas relações e comportamentos da vítima, atingindo também a sociedade. Estudos mostram que vítimas de abuso sexual tem tendência de abusar sexualmente de outras vítimas, daí a importância do presente estudo para explanar sobre as características do abuso sexual, modos de identifica-lo e a importância da sua notificação (Santos \& Ippolito, 2009).

O objetivo deste trabalho é contribuir para que os graduandos e profissionais da área de Odontologia estejam aptos para identificar e notificar abuso no ambiente odontológico, por meio da análise comportamental e de manifestações orofaciais, assim como incentivar a discussão do tema e propagar informação.

\section{Metodologia}

Este estudo consiste de uma revisão de literatura, qualitativa do tipo integrativa (Estrela, 2018). Por meio de consultas nas bases de dados: Google Acadêmico, SciELO, BVS e PubMed, foram buscados artigos entre os anos de 1990 a 2021, preferencialmente com as palavras chaves: Abuso Sexual Infantil, Notificação Compulsória de Abuso, e Doença Sexualmente Transmissível.

\section{Revisão da Literatura}

\subsection{Tipos de maus-tratos infantis}

Na legislação brasileira, maus tratos podem ser definidos como qualquer forma de negligência, exploração, violência, opressão, discriminação e crueldade, praticados contra a criança, sendo a violência entendida por toda ação danosa à vida e também à saúde do indivíduo, caracterizando maus tratos (Alves \& Cavalcanti, 2003; Silva, Cavalcanti \& Cavalcanti, 2017).

Crianças e adolescentes, por sua maior vulnerabilidade e dependência, são frequentemente vítimas de atos abusivos (Alves, \& Cavalcanti, 2003). E como já mencionado anteriormente, os maus tratos podem ser divididos em abuso sexual, físico, psicológico e negligência (Carneiro, 2020; Salazar et al., 2021).

Embora a violência infantil possa acontecer em ambos os sexos, vale ressaltar que o abuso físico acontece predominantemente em crianças do sexo masculino, já o abuso sexual em crianças do sexo feminino (Carneiro, 2020).

Tal violência é independente de classe social, cultura ou religião, e pode causar nas vítimas sérias consequências psicológicas, sociais, e danos sexuais em casos de abuso sexual (Alves et al., 2016; Florentino, 2015).

A partir disso, será descrito sobre cada tipo de abuso.

\subsection{Abuso físico}

Geralmente é a agressão à criança mais fácil de ser reconhecida, sendo considerado todo ato com uso de força física realizado com o intuito de lesionar, ferir, ou provocar dor à uma criança, ou seja, é caracterizado pelo trauma provocado em uma criança de forma intencional, que pode ser considerado desde uma leve palmada como forma de educar, porém, nesse caso a situação é discutível, apesar de alguns países como a Suíça e Dinamarca considerarem inadmissíveis a punição física 
como modo de educar. A gravidade da violência física é variada, contudo, pode levar a vítima a morte (Alves \& Cavalcanti, 2003; Pires \& Miyazaki, 2005; Silva et al., 2011).

Em geral, essa forma de violência está relacionada com a maneira do agressor lidar com situações de estresse emocional e desiquilíbrio, inclusive crianças espancadas comumente convivem em um ambiente familiar frequentemente exposto a essas situações, assim como são agredidas por pessoas que consomem álcool excessivamente, praticam delitos e também já foram abusadas fisicamente na infância (Silva et al., 2011).

Para o agressor, pode ser considerado uma forma de educar a criança, pela dificuldade em se relacionar com ela, ou ainda em forma de castigos corporais, como forma de resolver seus problemas (Carneiro, 2020).

O abuso físico é provocado na intenção de produzir dor, por meio de beliscões, socos, tapas, puxões de orelha, sufocamento, espancamento, queimaduras com água quente ou uso de objetos como, cintos, chinelos, cordas, ferro elétrico, intoxicação com psicofármacos, fios e brasa de cigarro. A presença de freio labial lacerado em bebês é considerado um sinal patognomônico, associado ao ato do agressor forçar a entrada da colher ou mamadeira na cavidade bucal, quando o bebê recusa a ingestão de alimentos ou apresenta choro persistente (Carneiro, 2020; Crespo et al., 2011; Granville-Garcia et al., 2006; Pires \& Miyazaki, 2005; Silva et al., 2011).

Durante um espancamento as áreas mais comuns de serem atingidas são pescoço e cabeça, e podem ser observadas também contusões, equimoses, abrasões, lacerações de lábios e de língua, machucados no canto da boca, queimaduras, hematomas e fraturas nos tecidos duros e moles da boca e outras regiões do corpo. Vale dizer que lesões nos dentes são comuns, como luxações e deslocamentos (extrusão e intrusão), avulsão, perda precoce, as alterações de coloração indicando necrose pulpar, e geralmente os dentes anteriores são os mais acometidos (Carneiro, 2020; Crespo et al., 2011; GranvilleGarcia et al., 2006; Pires \& Miyazaki, 2005; Silva et al., 2011).

O trabalho infantil também é considerado abuso físico, pelo fato de crianças trabalharem longos períodos, não frequentando em alguns casos a escola, não sendo remunerados, logo sendo considerado trabalho escravo. Tais condições de trabalho citadas anteriormente, dificultam o desenvolvimento físico, intelectual e emocional da criança (Silva et al., 2011).

\subsection{Abuso psicológico}

O abuso psicológico infantil é toda a ação ou a omissão com finalidade de causar danos à autoestima, ao desenvolvimento ou à identidade da criança, se apresentando simultaneamente aos outros tipos de abuso, e sendo mais difícil de detectar e provar (Alves et al., 2016, Carneiro, 2020).

Este abuso, pode ser provocado no meio familiar pelos pais ou cuidadores, assim como no meio extrafamiliar, pelos amigos, inclusive por profissionais de saúde e professores, podendo ser justificada pelos agressores como crianças que são más e desobedientes, defendendo a disciplina de modo severo. De forma intencional, esse abuso tem a finalidade de provocar sentimento de culpa, diminuição da autoestima da vítima e causar danos emocionais. Pode se manifestar quando os responsáveis da vítima não interrompem a violência doméstica, o uso álcool e drogas, atos delinquentes e não prestam tratamento psicológico quando indicado. Geralmente os agressores agridem as vítimas por meio de humilhação, insultos constantes, desvalorização, ameaças (chantagens), afastamento dos familiares e amigos, rejeição, abandono e omissão de carinho (Carneiro, 2020; Crespo et al., 2011; Pires \& Miyazaki, 2005; Silva et al., 2011).

\subsection{Negligência}

É um dos tipos de maus tratos mais comuns, e se define pela falha dos pais ou responsáveis pelo menor de idade em prover cuidados básicos (Alves et al., 2016, Carneiro, 2020). 
Para sua ocorrência, dois aspectos devem ser levados em consideração: a omissão do ocorrido e que este fato aconteça de forma crônica. A negligência pode ser exemplificada pelo responsável que não proporciona à criança: alimentação adequada, cuidados médicos, odontológicos e psicológicos, privação de medicação, vacinação, cuidados de higiene, vestimenta ideal para o clima, frequência adequada escolar, assim como acompanhamento e suporte das atividades escolares (Crespo et al., 2011; Pires \& Miyazaki, 2005; Silva et al., 2011).

Sobre a negligência odontológica, é quando os pais ou responsáveis tem acesso à informação e também acesso aos atendimentos, entretanto, não buscam ou não seguem o atendimento (tratamento) da criança, resultando em complicações orais, como cáries, gengivites e traumas na região orofacial (Carneiro, 2020).

\subsection{Abuso sexual}

O abuso sexual infantil geralmente é praticado por uma pessoa da família ou próxima, aumentando a chance de consecutivos abusos. Quanto sua definição, esse tipo de abuso acontece quando o agressor usa a vítima como objeto de satisfação sexual, envolvendo contato físico ou não, assim como toques, carícias, exibicionismo, penetração digital e genital, beijo na boca, sexo oral, uso de imagens e gravações da vítima para produção de conteúdo pornográfico (Alves et al., 2016; Crespo et al., 2011; Florentino, 2015; Pires \& Miyazaki, 2005; Silva et al., 2011).

O abuso sexual tem um diagnóstico difícil, pois muitos casos deixam de ser relatados por outros membros da família, e também pela questão que esse abuso é caracterizado por progressão, e a medida que a criança vai crescendo (muitas delas se consentem), e acabam não procurando ajuda por não compreenderem de fato o que está acontecendo (Carneiro, 2020).

\subsection{Alterações físicas decorrentes do abuso sexual}

A criança deve ser observada desde o momento em que se direciona para a sala de atendimento, onde pode ser analisada presença de sangue nas roupas, alterações na marcha, pois após o abuso algumas vítimas podem apresentar sangramento, dor, dificuldade para caminhar e também para sentar-se na cadeira odontológica devido ao rompimento do hímen, lesão no ânus e na vagina. Podem apresentar também aparência de gravidez precoce e o ato de coçar as áreas genitais constantemente, sintoma decorrente de infecções sexualmente transmissíveis. O profissional deve atentar-se a vestimenta da criança, que pode não ser compatível com o clima, levantando hipótese de tentativa de ocultação de lesões visíveis no corpo na vítima (Alves \& Cavalcanti, 2003; Conceição et al., 2020; Pires \& Miyazaki, 2005; Santos \& Ippolito, 2009; Silva et al., 2011).

Algumas infecções transmissíveis sexualmente apresentam manifestações na cavidade oral, como Condiloma Acuminado, Sífilis, Gonorreia e Herpes tipo II e fortalecem o indício de que a vítima foi abusada sexualmente, principalmente quando é descartada a possibilidade de contaminação vertical durante o parto ou por transfusão sanguínea (Alves \& Cavalcanti, 2003; Alves et al., 2016; Gondim, Munõz, \& Petri, 2011; Menoli, Felipetti, Golff, \& Ludwig, 2008; Santos et al., 2021).

Identifica-se que parte das alterações repercutidas do abuso sexual, se apresentam no complexo orofacial, sendo o cirurgião-dentista privilegiado quanto a possibilidades de identificação da violência sexual infantil, principalmente por parte dos Odontopediatras, que tem contato estreito e precoce, acompanhando a criança desde o período da infância até a adolescência. As lesões que podem estar associadas ao abuso sexual são: lacerações nos freios labiais e linguais, hematoma na face interna dos lábios, pelos pubianos, marcas de mordida associadas a equimoses de sucção, presença de sêmen, e também de petéquias e eritema no palato, sugerindo sexo oral forçado (Alves \& Cavalcanti, 2003; Alves et al., 2016; Carneiro, 2020; Carvalho \& Ferreira, 2019; Crespo et al., 2011; Junior, Pagel, Campos \& Miotto, 2015; Massoni, Ferreira, Aragão, Menezes \& Colares, 2010; Pires \& Miyazaki, 2005; Souza, Rodrigues, Zocratto \& Oliveira, 2017; Rover et al., 2020; Santos et al., 2021). 


\subsection{Características comportamentais e emocionais da vítima de abuso sexual}

O ser humano se comunica de forma verbal e não verbal e o comportamento da criança é expressado baseando-se nas suas vivências. Desta forma, vítimas de abuso sexual apresentam padrões de comportamentos específicos, sugerindo o levantamento de suspeitas, auxiliando também na análise conjunta das observações das alterações físicas encontradas na vítima (Crespo et al., 2011; Santos \& Ippolito, 2009; Santos et al., 2021).

Assim, existem características que podem estar associadas a vítima de abuso sexual, como: quadro de depressão, ansiedade, bipolaridade, agressividade, tentativa de suicídio, a prática de delitos, brincadeiras sexuais, fugir de casa, aversão ao ter que voltar para casa, desconforto ao toque físico, desconforto na presença dos pais, desconfiança, enurese, choro sem causa aparente, obesidade, anorexia, e também atraso no desenvolvimento intelectual, motor e na linguagem (Santos \& Ippolito, 2009, Florentino, 2015).

Cada criança tem uma forma de desenvolvimento diferente, assim como a reação, que é de forma individual a determinadas situações que são expostas. Alguns fatores são determinantes para influenciar no dano causado pelo abuso sexual, como a idade do abuso (quanto mais jovem for a criança, mais âmbitos da vida da criança podem ser atingidos, assim como maior gravidade), o tempo de abuso (uma criança que sofre abuso por muitos anos tem mais chance de desenvolver mais danos que uma vítima que sofreu apenas um episódio), o grau da violência, ou seja, quando envolve ameaça, outras formas de violência aumenta-se a gravidade, a proximidade do agressor com a vítima (quanto maior for o vínculo, por exemplo pessoas que moram na mesma casa), e também, a ausência de uma pessoa protetora, pois quando a criança não tem uma pessoa próxima que sente confiança, ela acaba sem refúgio para ter apoio depois da violência, assim como para pedir socorro e ter proteção para que o ato do abuso não aconteça novamente (Santos \& Ippolito, 2009; Florentino, 2015).

Podem ocorrer também consequências na vida adulta da vítima de abuso sexual, como problemas para criar vínculos, pela desconfiança gerada à outros seres humanos, onde esse sentimento é trazido para a vida adulta causando medo de criar relações mais íntimas, causando sentimentos de baixa autoestima, culpa, e depressão prolongada por medo da intimidade (Santos \& Ippolito, 2009).

Dificuldade de distinguir sexo e afeto, principalmente quando são abusadas por familiares, a concepção de afeto e sexo é distorcida (levando a busca constante de parceiros para se sentir amado na vida adulta), a tendência para a prostituição, pois essas crianças entenderam no período do abuso que o sexo era o melhor delas para oferecer para alguém, e logo se sentiam importantes, valorizadas. Quando adulta, essa criança tem necessidade ainda de suprir esse sentimento, mantendo sua autoestima, logo se sentem valorizadas se prostituindo, contudo, isso não ocorre com todas as crianças abusadas (Ferreira et al., 2001; Santos, \& Ippolito, 2009).

E também, a dependência de drogas ilícitas, pois as drogas causam sensações que podem ajudar na fuga da realidade, dos sentimentos negativos causados pelo abuso (Lira et al., 2017; Santos \& Ippolito, 2009).

\subsection{Características comportamentais do abusador sexual}

Grande parte dos casos de abuso sexual são praticados por agressores de dentro da família ou por pessoas que estão mais próximas da vítima, sendo assim, os abusos acontecem em 54\% no âmbito familiar e $43 \%$ extrafamiliar. Em primeiro lugar, há uma maior prevalência do acometimento pelo pai e pela mãe, sucedendo pelo parceiro da mãe, avós e tios. A ocorrência do abuso sexual dentro da família ocorre independentemente da condição socioeconômica, crença e cultura. Entre 3 a 4 anos, as crianças estão mais predispostas a sofrerem o abuso, por apresentarem choro e gritos incontroláveis (Conceição et al., 2020; Massoni et al., 2010; Santos et al., 2021).

Algumas características podem estar associadas ao abusador, como dificuldade financeira, ter sofrido algum tipo de abuso na infância, o uso de substâncias ilícitas, mãe ou pai jovem, desemprego, companheiros que não sejam pais biológicos 
da criança, gestação/paternidade indesejada, infecções pós parto e doenças mentais (Alves et al., 2016; Santos et al., 2021). Entretanto, vale salientar que tais fatores não podem ser considerados como causa principal da ocorrência das agressões, visto que, muitos pedófilos são descritos como trabalhadores e que apresentam zelo por sua família (Alves et al., 2016).

\subsection{Notificação compulsória}

A notificação compulsória do abuso sexual infantil é uma comunicação entre qualquer pessoa, órgão ou profissional da saúde e instituições competentes especializadas pela proteção da criança, como o Conselho Tutelar, Vara da Infância e da Juventude, Órgão de Proteção à Criança e ao Adolescente ou Delegacia de Polícia mais próxima. Para realizar a notificação, os órgãos podem ser notificados por ligação, por escrito ou presencialmente de forma anônima ou não. Os órgãos acionados se responsabilizam pela averiguação das informações e encaminhamento para os setores de ação, interrompendo a violência (Alves et al., 2016; Crespo et al., 2011; Ministério da Saúde, 2002; Santos et al., 2021).

A notificação pode ser feita por qualquer pessoa, seja profissional da saúde ou não, mas a notificação compulsória é um documento, que deve ser acessado e preenchido presencialmente ou virtualmente e sempre preenchido em duas vias. No caso dos profissionais da saúde deve ser realizada uma anamnese detalhada informando sobre a localização, tamanho, radiografias e fotografias das lesões encontradas. O profissional deve recolher o depoimento da vítima e dos responsáveis separadamente, justificando o aparecimento das lesões encontradas, assim como os meios usados para sua execução. Neste momento, pode ser evidenciada divergências nas declarações. Durante a escuta deve estar presente outra pessoa da equipe, que cumprirá a função de testemunha. Todas as informações colhidas devem ser incluídas no prontuário e mantidas em sigilo (Alves et al., 2016; Carneiro, 2020; Crespo et al., 2011; Menoli et al., 2008; Ministério da Saúde, 2002; Santos et al., 2021).

A notificação compulsória além de interromper o processo de violência, é um meio de gerar dados para as autoridades legais, indicando suas proporções, auxiliando no direcionamento das ações que acolhem vítimas, agressores e analisando seus impactos na sociedade de forma geral. Devido a ampla importância do ato de notificar a violência, o profissional da saúde recebe essa responsabilidade de forma obrigatória (Alves \& Cavalcanti, 2003; Alves et al., 2016; Crespo et al., 2011; Santos et al., 2021).

A lei 8.069 de 13 de julho de 1990 que institui o Estatuto da Criança e do Adolescente, no artigo 13, dispõe "os casos de suspeita ou confirmação de castigo físico, de tratamento cruel ou degradante e de maus-tratos contra criança ou adolescente serão obrigatoriamente comunicados ao Conselho Tutelar da respectiva localidade, sem prejuízo de outras providências legais." (Brasil, 1990, art. 13).

E ainda, segundo esta mesma lei, artigo 245:

Deixar o médico, professor ou responsável por estabelecimento de atenção à saúde e de ensino fundamental, pré-escola ou creche, de comunicar à autoridade competente os casos de que tenha conhecimento, envolvendo suspeita ou confirmação de maus-tratos contra criança ou adolescente: pena - multa de três a vinte salários de referência, aplicando-se o dobro em caso de reincidência. (Art. 245).

Ainda que a notificação compulsória seja uma obrigação, muitos profissionais acabam não notificando casos suspeitos por falta de conhecimento sobre o assunto, medo do diagnóstico incorreto, o medo de se envolverem na situação, o medo do confronto com os responsáveis pelo menor e ainda acreditando que precisam ter confirmação do abuso para notificar, não tendo conhecimento específico sobre as lesões decorrentes do abuso, assim como os sinais comportamentais e falta de conhecimento das legislações vigentes. As deficiências citadas anteriormente estão relacionadas também a falta de discussão do assunto durante a graduação (Alves \& Cavalcanti, 2003; Alves et al., 2016; Crespo et al., 2011; Ministério da Saúde, 2002; Santos et al., 2021; Silva et al., 2017). 


\section{Discussão}

O abuso sexual infantil é um problema social que ocorre independente de classe, etnia, e nível educacional, muitas vezes não é diagnosticado e nem notificado, o que faz com que os números não coincidam com a realidade (Alves et al., 2016; Carneiro, 2020). E no âmbito legal, o cirurgião-dentista é obrigado por lei, a notificar situações de violência infantil, de acordo com o ECA (Brasil, 1990; Alves \& Cavalcanti, 2003).

Na presença de suspeitas de maus tratos pelo profissional cirurgião-dentista, esta deve basear-se principalmente na junção das informações adquiridas na anamnese, com as informações do exame físico/clínico e também de exames complementares (Carneiro, 2020).

O profissional cirurgião-dentista deve sempre procurar a história de qualquer lesão, caso tenha uma natureza suspeita, sendo dever acolher a vítima, descrever todas as lesões de acordo com a região, tamanho e aspecto, não deixar de observar toda a face e pescoço, pois o diagnóstico do abuso infantil se dá por meio de indicadores físicos e comportamentais com a análise de sinais e sintomas comuns à crianças que são abusadas e negligenciadas (Alves, \& Cavalcanti, 2003, Carneiro, 2020).

A partir disso, mediante nova consulta com a criança, o profissional deve se atentar a observar e avaliar não somente as questões físicas, mas também toda a parte psicológica da criança, onde deve ter uma capacidade de interpretação de linguagem emocional, bem como o ambiente familiar, buscando informações com os pais ou acompanhante, tentando juntar o maior número de informações que levam ao diagnóstico, contudo, a suspeita de abuso sexual infantil já é suficiente para denúncia (Alves \& Cavalcanti, 2003; Carneiro, 2020; Salazar et al., 2021).

A revelação pode ocorrer em qualquer momento pela criança/adolescente, daí os profissionais devem estar preparados no que dizer, e como conduzir o caso, sendo necessário acreditar em todo o relato da vítima, tendo empatia e compreensão diante do diálogo com a mesma, e não prometer sigilo, contudo passar segurança dizendo que pessoas irão ajudar (Carneiro, 2020).

Entretanto, ainda existe por parte dos cirurgiões-dentistas falta de conhecimento sobre assuntos relacionados à violência infantil, bem como dificuldade em identificar os principais sinais/manifestações do abuso sexual em crianças e adolescentes (Alves et al., 2016).

Diante da coleta de informações, muitos profissionais também apresentam dúvidas sobre como deve ser a maneira correta de agir, e partindo desse pressuposto, protocolos de orientação profissional são necessários para ajudá-los tanto no diagnóstico, quando no registro da violência infantil, proporcionando maior segurança para sua realização (Carneiro, 2020).

Em seu estudo, Carneiro (2020) relata um questionário realizado na cidade de Cravinhos (São Paulo), com 19 cirurgiões-dentistas, onde constatou-se que 73,7\% desses profissionais nunca tiveram nenhum tipo de orientação sobre tal assunto, relatando ainda, uma entrevista realizada na atenção básica de quatro municípios na região de São José do Rio Preto, com um total de 54 profissionais, e $96,2 \%$ não foram orientados sobre como é o preenchimento da ficha de notificação compulsória.

A comunidade odontológica por ter um papel essencial no diagnóstico e prevenção dos maus tratos, no tratamento das lesões orofaciais derivadas do abuso e auxilio nas notificações da violência infantil, deve ser conscientizada e alertada sobre a fundamental importância no combate ao abuso e negligências infantis, levando em consideração, que pode responder legalmente a não realização das deliberações do ECA (Alves \& Cavalcanti, 2003; Carneiro, 2020).

Nota-se que a denúncia não é fácil, contudo, garantir a segurança das crianças é essencial, além disso notificar significa contribuição e assumir a responsabilidade social enquanto um profissional da saúde (Carneiro, 2020).

A partir do exposto, é necessário que este assunto seja mais falado e abordado de forma específica durante a graduação dos futuros odontólogos, para que estes se tornem melhores profissionais frente ao diagnóstico e conduta de maus tratos infantis. 


\section{Considerações Finais}

Pelo fato de algumas das lesões provenientes dos maus tratos, inclusive do abuso sexual comprometerem a região orofacial, é indispensável que graduandos e profissionais do curso de Odontologia estejam aptos para identificarem e denunciarem os casos de suspeita de abuso sexual de vulnerável.

Os maus tratos infantis e suas consequências são um problema social e toda população deve ter conhecimento sobre contribuir para o processo de prevenir e diminuir a violência infantil e dos adolescentes.

A discussão do tema na área da saúde é importante já que o cirurgião-dentista faz parte da porta de entrada do SUS, Atenção Primária de Saúde e faz parte da Equipe de Saúde da Família.

Esse trabalho pode auxiliar gestores da saúde em projetos de acolhimento de crianças violentadas, ações de promoção e prevenção da violência contra a criança.

\section{Referências}

Alves, M. A., Da Fonseca. B. A., Soares, T., \& Alexandria, A. K. (2016). Importância do cirurgião-dentista no diagnóstico de abuso sexual infantil-revisão de literatura. Revista Brasileira de Odontologia Legal, 3 (2). https://www.researchgate.net/publication/309439343_Importancia_do_cirurgiaodentista_no_diagnostico_de_abuso_sexual_infantil_-_revisao_de_literatura .

Alves, P. M., \& Cavalcanti, A. L. (2003). Diagnóstico do abuso infantil no ambiente odontológico. Uma revisão da literatura. Ciênc Biol Saúde Ponta Grossa, 9 (3), 29-35. https://revistas2.uepg.br/index.php/biologica/article/view/367. https://doi.org/10.5212/publicatio\%20uepg.v9i3.367.

Brasil. (1990). Lei n. 8.069, de 13 de julho de 1990. Dispõe sobre o Estatuto da Criança e do Adolescente, e dá outras providências. Presidência da República, casa civil. https://www.planalto.gov.br/ccivil_03/leis/18069.htm.

Carneiro, C. S. de A. (2020). Conduta do cirurgião-dentista ante a violência infantil: revisão de literatura. 2020. Trabalho de Conclusão de Curso - Escola Bahiana de Medicina e Saúde Pública, Salvador. http://www.repositorio.bahiana.edu.br/jspui/handle/bahiana/4610.

Carvalho, A. B., \& Ferreira, R. B. (2019). Principais manifestações das doenças sexualmente transmissíveis acometidas na cavidade oral. https://dspace.uniceplac.edu.br/bitstream/123456789/217/1/Alan_Brito_0003110.pdf.

Conceição, M. I. G., Costa, L. F., Penso, M. A., \& Williams, L. C. A. (2020). Abuso sexual infantil masculino: sintomas, notificação e denúncia no restabelecimento da proteção. Psicol. Clin., $32 \quad(1), \quad 101-121$. http://pepsic.bvsalud.org/scielo.php?script=sci_abstract\&pid=S010356652020000100006\&lng=pt\&nrm=iso. http://dx.doi.org/10.33208/PC1980-5438v0032n01A05.

Crespo, M., Andrade, D., Alves, A. L. S., \& Magalhães, T. (2011). O papel do médico dentista no diagnóstico e sinalização do abuso de crianças. Acta Med Port, 24, 939-948. http://www.paediatricdentistry.com/docs/papel_medico_dentista_diagnostico_sinalizacao_abuso_de_criancas.pdf.

Estrela, C. (2018). Metodologia Científica: Ciência, Ensino, Pesquisa. Editora Artes Médicas. Acesso em: 09 de setembro de 2021.

Ferreira, A. L. et al. (2001). Guia de atuação frente a maus-tratos na infância e na adolescência, Orientações para pediatras e demais profissionais que trabalham com crianças e adolescentes, $2^{\circ}$ ed., Rio de Janeiro. https://www.sbp.com.br/fileadmin/user_upload/maustratos_sbp.pdf.

Fisher-Owens, S. A., Lukefahr, J. L., \& Tate, A. R. (2017). Oral and dental aspects of child abuse and neglect. American Academy of pediatrics, 140 (2). https://www.co4kids.org/sites/default/files/AAP_DentistReport_2017.pdf.

Florentino, B. R. B. (2015). As possíveis consequências do abuso sexual praticado contra crianças e adolescentes. Fractal: Revista de Psicologia, 27 (2), 139144. https://www.scielo.br/j/fractal/a/dPY6Ztc8bphq9hzdhSKv46x/?lang=pt\&format=html.

Gondim, R. M. F., Muñoz, D. R., Petri, V. (2011). Violência contra a criança: indicadores dermatológicos e diagnósticos diferenciais. An Bras Dermatol., 86 (3), 527-536. https://www.scielo.br/j/abd/a/SHS7BYznTnKjL7pTj4pn6nc/abstract/?lang=pt. https://doi.org/10.1590/S0365-05962011000300015.

Granville-Garcia, A. F., Silva, M. J. F., \& Menezes, V. A. de. (2006). Maus-tratos a crianças e adolescentes: um estudo em São Bento do Uma, PE, Brasil. Pesquisa Brasileira em Odontopediatria e Clínica Integrada, 8 (3). https://www.redalyc.org/pdf/637/63711711007.pdf.

Junior, M. F. S., Pagel, M. D., Campos, D. M. K. S., \& Miotto, M. H. M. B. (2015). Conhecimento de acadêmicos de Odontologia sobre maus-tratos infantis. Arquivos em Odontologia, 51 (3), 2015. https://periodicos.ufmg.br/index.php/arquivosemodontologia/article/view/3676

Lira, M. O. de S. C. e. et al. (2017). Abuso sexual na infância e suas repercussões na vida adulta. Texto Contexto Enferm, 26 (3). https://www.scielo.br/j/tce/a/Fq8Cg6F7bcbZRNhxFqKTMTR/abstract/?lang=pt.

Massoni, A. C. L. T., Ferreira, A. M. B., Aragão, A. K. R., Menezes, V. A. de., \& Colares, V. (2010). Aspectos orofaciais dos maus-tratos infantis e da negligência odontológica. Ciência \& Saúde Coletiva, $15 \quad$ (2), 403-410. https://www.scielo.br/j/csc/a/5LQvscgQpBmcgH3NKZnrhfG/?lang=pt. https://doi.org/10.1590/S1413-81232010000200016.

Menoli, A. P., Felipetti, F. A., Golff, F., \& Ludwig, D. (2008). Manifestações bucais de maustratos físicos e sexuais em crianças - conduta do cirurgião dentista. Varia Scientia, 8 (14), 11-22. http://e-revista.unioeste.br/index.php/variascientia/article/view/2602. 
Research, Society and Development, v. 10, n. 14, e479101422370, 2021

(CC BY 4.0) | ISSN 2525-3409 | DOI: http://dx.doi.org/10.33448/rsd-v10i14.22370

Ministério da Saúde. (2002). Notificação de maus-tratos contra crianças e adolescentes pelos profissionais de saúde: um passo a mais na cidadania em saúde. Brasília - DF, Editora MS. https://bvsms.saude.gov.br/bvs/publicacoes/notificacao_maustratos_criancas_adolescentes.pdf.

Pires, A. L. D., \& Miyazaki, M. C. O. S. (2005). Maus-tratos contra crianças e adolescentes: revisão da literatura para profissionais da saúde. Arq Ciênc Saúde, 12 (1), 42-9. https://repositorio-racs.famerp.br/Vol-12-1/08\%20-\%20id\%20102.pdf.

Rover, A. de L. P. et al. (2020). Violência contra a criança: indicadores clínicos na odontologia. Brazilian Journal of Development, 6 (7), 43738-43750. https://www.brazilianjournals.com/index.php/BRJD/article/view/12740.

Salazar, T. S., Sá, M. M., \& Veloso, K. M. M. (2021). Nível de conhecimento de profissionais e estudantes de odontologia sobre abuso infantil: uma revisão integrativa. https://portalabol.com.br/rbol/index.php/RBOL/article/view/364/283.

Santos, B. C. F. dos. et al. (2021). A notificação e prevenção do abuso infantil pelos profissionais da saúde: revisão de literatura. Revista de Odontologia Contemporânea, 5 (1), 1-8. https://rocfpm.com/index.php/revista/article/view/108. https://doi.org/10.31991/v5n12021rocabuso.

Santos, B. R. dos., \& Ippolito, R. (2009) Guia de referência: construindo uma cultura escolar de prevenção à violência sexual. São Paulo: Childhood, 4 ed. https://www.childhood.org.br/childhood/publicacao/Guia_de_Refere\%CC\%82ncia_4_Edic\%CC\%A7a\%CC\%83o_2020_PAG_DUPLA.pdf.

Silva, D. G. da., Gava, L. L., \& Dell'Aglio, D. D. (2013). Sintomas e quadros psicopatológicos em supostas vítimas de abuso sexual: uma visão a partir da psicologia positiva. Aletheia, n. 40, 58-73. http://pepsic.bvsalud.org/scielo.php?script=sci_abstract\&pid=S1413-03942013000100006.

Silva, K. B. G. da, Cavalcanti, A. F. C., \& Cavalcanti, A. L. (2017). Maus-tratos infantis: conhecimentos e condutas dos cirurgiões-dentistas da Estratégia Saúde da Família de Guarabira-PB, Brasil. Revista Família, Ciclos de Vida e Saúde no Contexto Social, 5, 108-117. https://www.redalyc.org/journal/4979/497954891003/html/.

Silva, R. H. A. da. et al. (2011) Orientação profissional para o cirurgião-dentista: ética e legislação. Santos Editora, p. 457-471.

Souza, C. E. de, Rodrigues, I. F. M. de M., Zocratto, K. B. F., \& Oliveira, C. A. S. de. (2017). Violência infantil e a responsabilidade profissional do cirurgiãodentista - revisão de literatura. Revista Brasileira de Odontologia Legal, 4 (1). https://portalabol.com.br/rbol/index.php/RBOL/article/view/75. 